\title{
Correction to: Screening Adults for HIV Testing in the Outpatient Department: An Assessment of Tool Performance in Malawi
}

\author{
Corrina Moucheraud ${ }^{1}$ (1) $\cdot$ Risa M. Hoffman ${ }^{2} \cdot$ Kelvin Balakasi $^{3} \cdot$ Vincent Wong $^{4} \cdot$ Maria Sanena $^{3} \cdot$ Sundeep Gupta ${ }^{2}$. \\ Kathryn Dovel ${ }^{2,3}$
}

Published online: 12 September 2021

๑) Springer Science+Business Media, LLC, part of Springer Nature 2021

\section{Correction to: AIDS and Behavior}

https://doi.org/10.1007/s10461-021-03404-8

The original version of this article unfortunately contained an error, and it has been corrected with this erratum.

In the abstract for this article an error occurred after the text '... tools that include questions about sexual behavior and use of health services"; the following sentence should read "We compare a full tool (seven relevant questions) to a reduced tool (five questions, excluding sexual behavior measures) and to standard of care (two questions, never tested for HIV or tested $>12$ months ago, or seeking care for suspected STI)".

The original article has been corrected.

Publisher's Note Springer Nature remains neutral with regard to jurisdictional claims in published maps and institutional affiliations.

The original article can be found online at https://doi.org/10.1007/ s10461-021-03404-8.

Corrina Moucheraud

cmoucheraud@ucla.edu

1 Department of Health Policy and Management, Fielding

School of Public Health, University of California, 650

Charles E. Young Dr. S., 31-235A, Los Angeles, CA 90095 ,

USA

2 Division of Infectious Diseases, David Geffen School

of Medicine, University of California, Los Angeles, CA, USA

3 Partners in Hope, Lilongwe, Malawi

4 USAID Global Health Bureau, Washington, DC, USA 